\section{Timely use of Covid-19 vaccines could have saved thousands of lives}

Published online first on July 22, 2021. DOI: 10.20529/IJME. 2021.054

Keywords: Covid-19, vaccine, clinical trial, safety, protection against death.

Earlier we, TJJ and DD, had written in $I J M E$, that during the pandemic with high case-fatality in those above 65 and younger adults with chronic lung, heart or kidney diseases or diabetes, vaccination must be administered early as a lifesaving procedure (1). It was pointed out that protection delayed may be protection denied to drive home the urgency of vaccination for saving lives. At that time, Phase III vaccine trials were in progress and we had adequate data on safety, but efficacy had yet to be measured. Good immunogenicity had already been documented in Phases I and II in which there were no signals of safety problems. Efficacy was "on promise" when we argued for early vaccination of those at risk of death.

It has been distressing to read about countless deaths of people from Covid-19, during the months March to May 2021. The total number of deaths reported in the second wave (between March 11 and May 27, 2021) was over 160,000 (2). We believe that this number is an under-estimate because India does not practise public health surveillance and the authorities do not verify cause of death diagnosis at local levels. About 2000 Covid-19 deaths in Mumbai (60\% of total deaths) have occurred in the age group over 60 years (3). Till date only $31 \%$ of this age group in Mumbai has received two doses of the vaccine, the majority since the first week of March (3). In Kerala state, 2716 deaths (over $70 \%$ of total deaths) occurred in the age group above 60 years, between March and May (4).

Extrapolating from the Mumbai and Kerala data above, we attribute one lakh deaths $(65 \%$ of 160,000$)$ to Covid-19 among the over-60 population - lives that could have been saved with two doses of a vaccine given at the appropriate time. Government opened up vaccination to those above 60 years from the first week of March. There was no public education on the safety and efficacy of the two vaccines, and as a result vaccine hesitancy began growing through social media. By April 21 only 47\% of those of eligible age to receive vaccine had actually got at least one dose (5)

From the literature, we understand that all currently used Covid-19 vaccines with two-dose schedule offer near-100 per cent protection against life-threatening severity of Covid-19 - hence are life-saving if given twice, four weeks apart $(6,7)$. In order to be effective, the first dose should have been given in the first week of February 2021, and the second in the first week of March. Our plea for using vaccination to protect lives was made in October 2020, a clear three months earlier. The situation is tragic because we had safe vaccines made in India, and approved for emergency use on January 3, 2021 (8). Ethics and epidemiology demanded early and prioritised vaccination of those at risk of loss of life - for those who died without two doses of a vaccine, protection was denied by avoidable delay.

There were easily tracked data on those above 65 using Unique Identification Number (UID, Aadhaar) and on people with chronic diseases since many, if not most, are under healthcare either in public or private sector clinics/hospitals. Vaccination of these groups was the ethical responsibility of the pandemic management authorities.

We believe that over 100,000 lives were lost for want of an ethics-guided national policy to vaccinate for saving lives, in spite of our alert in IJME, and in spite of vaccines undergoing Phase III trials as we wrote in October 2020. Although many may believe that ethics applies only to what is done, it applies also to what was due but not done. Withholding a life-saving intervention is unethical, as in this case of having promising vaccine candidates available, but not offering them to those who were facing the risk of Covid-19-caused mortality. To be right for saving lives is greater than to be righteous by mindlessly following man-made rules and conventions, which are actually meant for the best interests of the public. What better interests are there, than saving lives?

T Jacob John (tjacobjohn@yahoo.co.in), Retired Professor, Christian Medical College, Vellore, Tamil Nadu INDIA; Dhanya Dharmapalan (corresponding author-drdhanyaroshan@gmail.com), Consultant in Paediatric Infectious Diseases, Apollo Hospitals, CBD Belapur, Navi Mumbai, INDIA; Jagdish Ratnanni (jagdish@thebillionpress.org), Director, 'Foundation of The Billion Press', and Faculty Member, Bhavan's SP Jain Institute of Management and Research.

\section{References}

1. John TJ, Dharmapalan D. Covid-19 vaccine trials and ethics: Protection delayed is protection denied. Indian J Med Ethics. 2021 Jan-Mar [cited 2021 May 21];6 (1):17-20. DOI: 10.20529/ IJME. 2020.104. Available from: https://ijme.in/articles/covid-19-vaccinetrials-and-ethics-protection-delayed-is-protection-denied/

2. Worldometers. Coronavirus. [cited 2021 May 21], Available from https://www.worldometers.info/coronavirus/country/india/\#graphdeaths-daily.

3. Debroy S. Mumbai: Not just deaths, cases among elderly dipping too, says officials. Times of India. 2021 May 28[cited 2021 May 29]. Available from: https://timesofindia.indiatimes.com/city/mumbai/ mumbai-not-just-deaths-cases-among-elderly-dipping-too-saysofficials/articleshow/83018810.cms 
4. Government of Kerala. Kerala: Covid-19 Battle. 2021 [cited 2021 May 28]. Available from https://dashboard.kerala.gov.in/deaths.php.

5. Ghosh A. Both Covishield \& Covaxin work, only $3-4$ in 10,000 infected post vaccine, Modi govt releases data. The Print. 2021 Apr 21[cited 2021 May 28]. Available from https://theprint.in/health/covid-deathsamong-people-aged-70-years-and-more-slightly-higher-in-2ndwave-govt-data-shows/643657/

6. Ella R, Reddy S, Jogdand H, Sarangi V, Ganneru B, Prasad S, et al. Safety and immunogenicity of an inactivated SARS-CoV-2 vaccine, BBV152: interim results from a double-blind, randomised, multicentre, phase 2 trial, and 3-month follow-up of a double-blind, randomised phase 1 trial. Lancet Infect Dis. 2021 Mar 8:S1473-3099(21)00070-0. Doi: 10.1016/S1473-3099(21)00070-0. Epub ahead of print.
7. Voysey M, Clemens SAC, Madhi SA, Weckx LY, Folegatti PM, Aley PK, et al. Oxford COVID Vaccine Trial Group. Safety and efficacy of the ChAdOx1 nCoV-19 vaccine (AZD1222) against SARS-CoV-2: an interim analysis of four randomised controlled trials in Brazil, South Africa, and the UK. Lancet. 2021 Jan 9;397(10269):99-111. Doi: 10.1016/S0140-6736(20)32661-1. Epub 2020 Dec 8. Erratum in: Lancet. 2021 Jan 9;397(10269):98.

8. Special Correspondent. India approves COVID-19 vaccines Covishield and Covaxin for emergency use. The Hindu. 2021 Jan 03[cited 2021 May 28]. Available from https://www.thehindu.com/ news/national/drug-controller-general-approves-covishield-andcovaxin-in-india-for-emergency-use/article33485539.ece

\section{Angry email to Reviewer \#2}

Published online first on October 8, 2020. DOI: 10.20529/JJME. 2020.103.

\section{Dear Reviewer \#2,}

Thank you for submitting your review comments on my diligently drafted manuscript. I appreciate the opportunity to evaluate your review but unfortunately (highlighted so you get the gist of this email and don't jump for joy prematurely), your reviews seem to lack the optimism I was looking for.

I think that you address an important issue when suggesting that I shorten the manuscript by five pages and replace the keywords of the paper with something more out of Shakespearean literature. But I regret to tell you that I cannot consider it seriously enough to chop the entire manuscript. Some of the ideas are interesting but I think they would have greater traction with someone pursuing a PhD in English Literature.

Unfortunately, as it would appear to a sane individual not choking on some kind of deep sadistic nihilism, the review process is only for ensuring a rigorous scientific standard not for exercising your spiteful, diabolical, remorseless, tyrannical and Mephistophelian (You see, I do use a dictionary sometimes) power over wretched researchers.

The volume of reviews to my manuscript is usually very high and I desk reject $99 \%$ of them. So do not consider yourself special. Since I can consider only a small proportion of reviews received, I must make the difficult decision of leaving most reviews out. It looks like you should read your daily horoscope before submitting such ridiculous reviews next time, or better still keep your tissues ready. Why do I alone have to cry every time?

I believe your literary prowess in reviewing manuscripts will be better placed elsewhere. Have you tried a career as a restaurant or movie reviewer? You would be surprised to find similar hate for ravenous reviewers in those two professions as well. Maybe you could form a cult and worship your satanic lord with sacrifices of manuscripts that took months to be written.

I do have a segment for general rants on my ResearchGate profile. You may submit your complaints there as a personal message. For public-facing outlets, we can engage in a wholly public debate on Twitter. If you are interested in submitting your opinion to those venues, please create a troll account and follow my given user accounts, to save your professional credibility from this public humiliation.

Thank you for submitting your reviews to me. I respectfully consider it a waste of my time.

I wish you success in finding a more suitable publication to practise the grammar Nazi in you, and I thank you for the work you have done because you definitely wrote this down in the basement of your parent's house after your girlfriend had left you for someone who doesn't necessarily say "tighten the text" every time she talks to you.

I am sorry that I did not accept your review this time and I hope you find success somewhere else in fulfilling your sadistic bloodthirsty appetite for reviews.

PS: Should you completely rewrite your review and include a token of apology along with accepting the manuscript as it is, I would consider going out of my way to endorse your research and review skills on Linkedln.

Sincerely,

Transfer desk to hell (another long submission process in this case)

Ankit Raj (drankitraj14@gmail.com), Orthopaedic Centre, Main Road, Prasad Bigha, Nawada, Bihar 805110 INDIA 